\title{
Применение термохимически стойких фильтрующих материалов в микроэлектронной промышленности
}

\author{
Е. Астахов, к. х. н. ${ }^{1}$, А. Астахова, к. б. н. ${ }^{2}$, П. Царин ${ }^{3}$, \\ И. Колганов, к. т. н. ${ }^{4}$, С. Горобец ${ }^{5}$
}

УДК 66.081.6 | ВАК 05.27.06

\begin{abstract}
На протяжении 28 лет Группа компаний "Обнинские фильтры" (г. Обнинск) производит микрофильтрационное оборудование для различных отраслей промышленности, и в частности для радиоэлектронной. В числе ее заказчиков более 1000 предприятий. Сегодня предприятие, занимающее лидирующее положение среди отечественных производителей микрофильтрационного оборудования, применяет целый спектр инновационных технологий, уникальные фильтрующие материалы. ГК "Обнинские фильтры" предлагает фильтрующие элементы на основе химически и термически стойких полимеров - фторопласта-4 и сверхвысокомолекулярного полиэтилена. Изготовленные из этих полимеров фильтры применяются для очистки жидких сред, в том числе химически агрессивных, например, деионизованной воды, кислот, щелочей, травителей, гальванических растворов, а также сжатых газов.
\end{abstract}

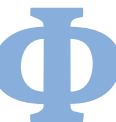
торопласт (ПТФЭ марки Ф-4, ГОСТ 10007-80) [1] исверхвысокомолекулярныйполиэтилен (СВМПЭ ТУ 2211-001-98386801) [2] используются группой компаний для производства поропластов марок "ЭКОПЛАСТ-Ғ» и «ЭКОПЛАСТ-РЕ», выполненных в виде многослойных полых цилиндров определенных размеров. На основе этих поропластов для очистки жидких и газообразных сред предлагаются фильтрующие элементы глубинного типа (рис. 1-3).

Инновационные пористые материалы марок «ЭКОПЛЕН-F» и "ЭКОПЛЕН-РЕ» в виде пористых пЛенок представляют собой низкоселективные мембраны, которые при фильтрации задерживают частицы в основном на поверхности (экранный механизм задержания). Однако благодаря широкому распределению пор по размерам они могут задерживать частицы и в материале (глубинный механизм задержания) [3]. Пористые пленки применяются в виде листов (реализуются рулонами), а также служат основой для производства гофрированных фильтрующих элементов (рис. 4). Рейтинги фильтрации поропластов составляют от 0,2 до 50 мкм и более (табл. 1).

ООО "Обнинские фильтры», генеральный директор ООО «Экспресс-Эко-Фильтр», генеральный директор. ООО «нПП Эко-Фильтр", генеральный директор

ООО "Обнинские фильтры", заведующий лабораторией.

ООО "Обнинские фильтры», заместитель генерального директора по науке и технологиям.
С помощью фильтрующих элементов от ГК «Обнинские фильтры» на предприятиях различных отраслей промышленности обеспечивается фильтрация главным образом химически агрессивных жидких и газообразных сред. Благодаря уникальным свойствам поропластов - высокой химической, механической и термической стойкости - они подходят и для других целей. Высокое качество изготовления поропластов на специальном

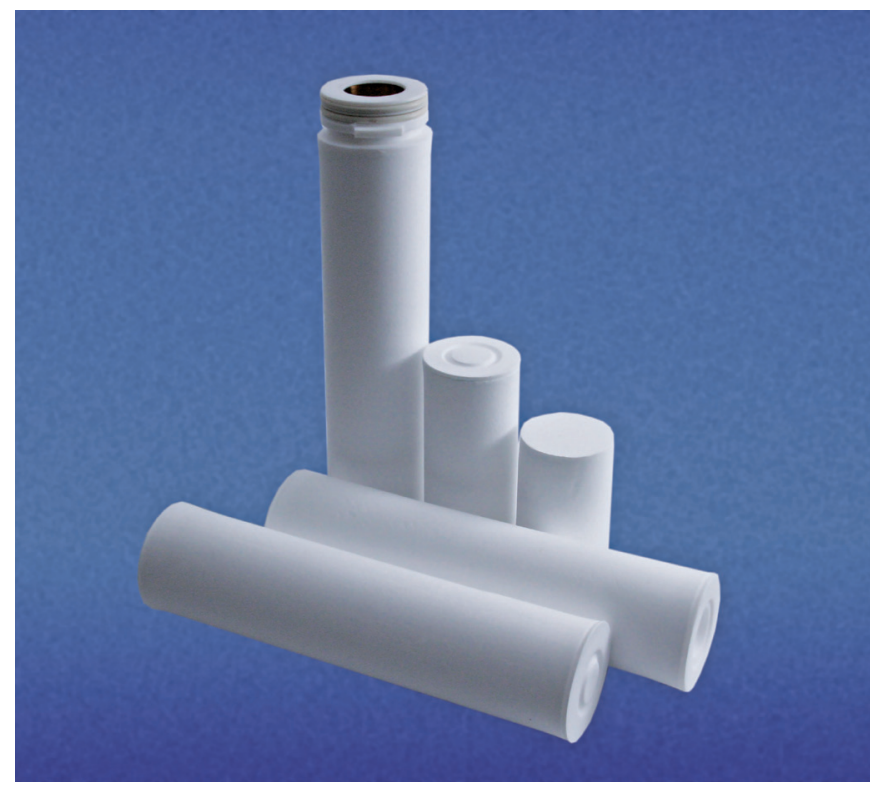

Рис. 1. Фильтрующие элементы на основе «ЭКОПЛАСТ-F» 


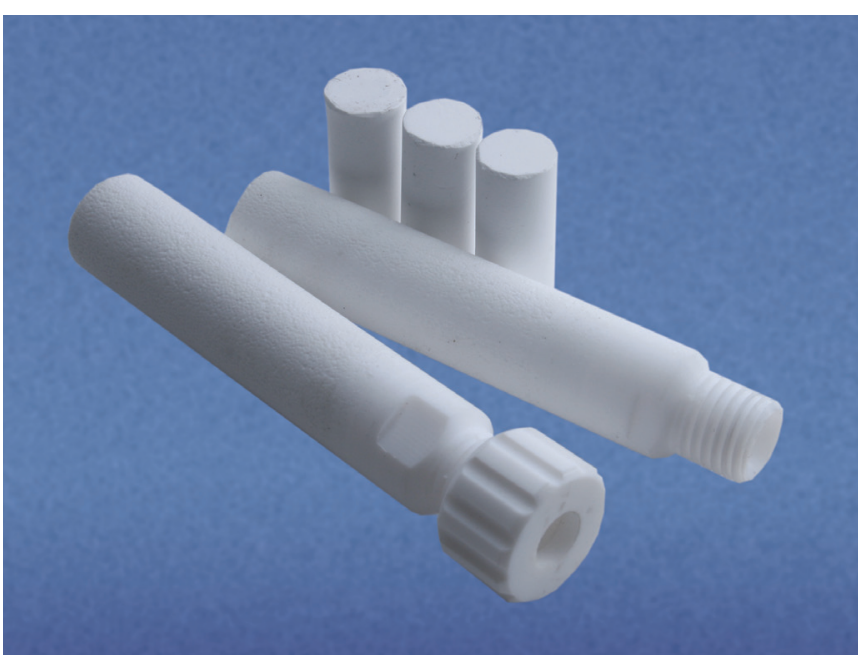

Рис. 2. Минипатроны «ЭКОПЛАСТ-F»

оборудовании позволяет жестко соблюдать и контролировать параметры выпускаемой продукции.

На предприятиях микроэлектронной промышленности фильтрационное оборудование группы компаний применяется для очистки жидких и газообразных сред, в частности $[4,5]$ :

- очистки сжатых газов, включая инертные, от аэрозолей и механических примесей;

- фильтрации обессоленной и деионизованной воды;

- фильтрации кислот и щелочей, травителей, смеси Каро, фоторезистов, в частности в замкнутом цикле;

- фильтрации электролитов, в частности в замкнутом цикле.

Рассмотрим подходы к решению перечисленных задач с использованием оборудования и материалов ГК «Обнинские фильтры».

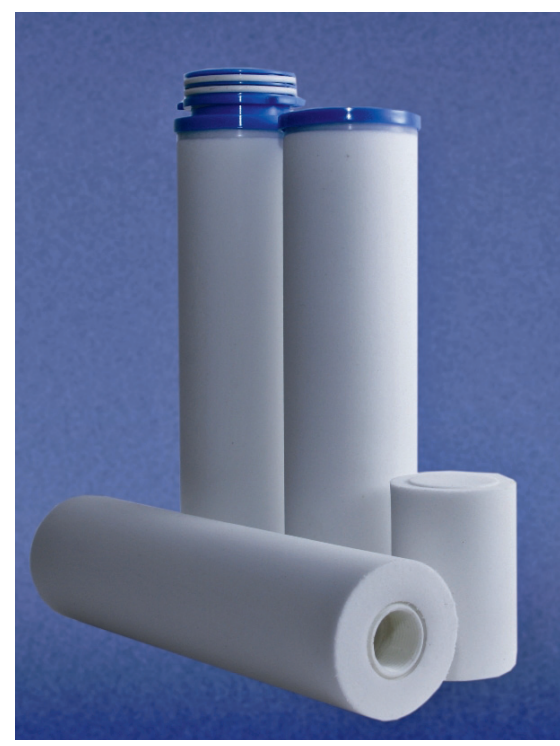

Рис. 3.

Фильтрующие элементы на основе «ЭКОПЛАСТ-РЕ»

\section{ФИЛЬТРАЦИЯ СЖАТОГО ВОЗДУХА И ТЕХНОЛОГИЧЕСКИХ ГАЗОВ}

Для очистки сжатых газов и воздуха с производительностью до 500 м³ / ч от механических частиц, аэрозолей и капель масла и воды предлагаются однопатронные фильтродержатели марки ДФП-201G и многопатронные фильтродержатели с тремя или пятью посадочными местами (рис. 5 и 6). Устройства можно соединить параллельно для организации непрерывного процесса фильтрации. Корпуса фильтродержателей изготовлены из нержавеющей стали марки AISI 316L, комплектуются манометром и спускным штуцером, оснащены посадочными местами под фильтрующие элементы высотой до 1000 мм. Максимальное рабочее давление фильтродержателей - до 1,6 МПа. Диаметр условного прохода входного и выходного патрубков - от 15 до 80 мм, подсоединение к линии - фланцевое или типа Tri-clamp.

Таблица 1. Технические характеристики поропластов

\begin{tabular}{|c|c|c|c|c|}
\hline $\begin{array}{l}\text { Техническая марка / } \\
\text { торговая марка поропласта }\end{array}$ & $\begin{array}{c}\text { ФМ-100 } \\
\text { «ЭКОПЛАСТ-F» }\end{array}$ & $\begin{array}{c}\text { ФМ-101 } \\
\text { «ЭКОПЛАСТ-РЕ» }\end{array}$ & $\begin{array}{c}\text { ФМ-400 } \\
\text { «ЭКОПЛЕН-F» }\end{array}$ & $\begin{array}{c}\text { ФМ-401 } \\
\text { «ЭКОПЛЕН-РЕ» }\end{array}$ \\
\hline Полимер & ПТФЭ & СВМПЭ & ПТФЭ & СВМПЭ \\
\hline Геометрия материала & \multicolumn{2}{|c|}{ Блок } & \multicolumn{2}{|c|}{ Пленка } \\
\hline Пористость, \% & $35-55$ & $35-50$ & $40-60$ & $40-50$ \\
\hline Диапазон рейтингов фильтрации, мкм & $0,2-20$ & $1-50$ & $0,2-5$ & $2-20$ \\
\hline $\begin{array}{l}\text { Удельная воздухопроницаемость, } \\
\mathrm{M}^{3} /\left(\mathrm{M}^{2} \cdot \mathrm{q} \cdot \mathrm{k} \text { Па } \cdot \mathrm{MM}\right)\end{array}$ & $0,5-25$ & $2-50$ & $50-300$ & $100-1500$ \\
\hline Прочность на разрыв, МПа & $2-4$ & $3-7$ & $3-6$ & $2-8$ \\
\hline Разрывное удлинение, \% & $40-90$ & $20-50$ & $50-120$ & $20-60$ \\
\hline
\end{tabular}


Конструкция фильтродержателей может быть двух видов: с отдельным конденсатосборником и бюджетный вариант, когда однопатронные фильтродержатели устанавливаются в линию колпаком вниз. Во втором случае колпак служит конденсатосборником. Выполненные в основании корпуса входной и выходной фланцы позволяют производить замену фильтрующих элементов при снятом колпаке без отсоединения внешних трубопроводов. Процесс фильтрации организован путем подачи рабочего газа снаружи внутрь по отношению к фильтрующему элементу.

В качестве фильтрующего материала для очистки газообразных сред используются фильтроэлементы глубинного типа марки "ЭКОПЛАСТ-F» с рейтингом фильтрации от 0,2 до 20 мкм и гофрированного типа марки "ЭКОПЛЕН-F» с рейтингом фильтрации от 0,2 до 5 мкм. Рабочая температура фильтроэлементов марки «ЭКОПЛАСТ-F» до $160^{\circ} \mathrm{C}$, а для марки «ЭКОПЛЕН-F»до $135^{\circ} \mathrm{C}$.

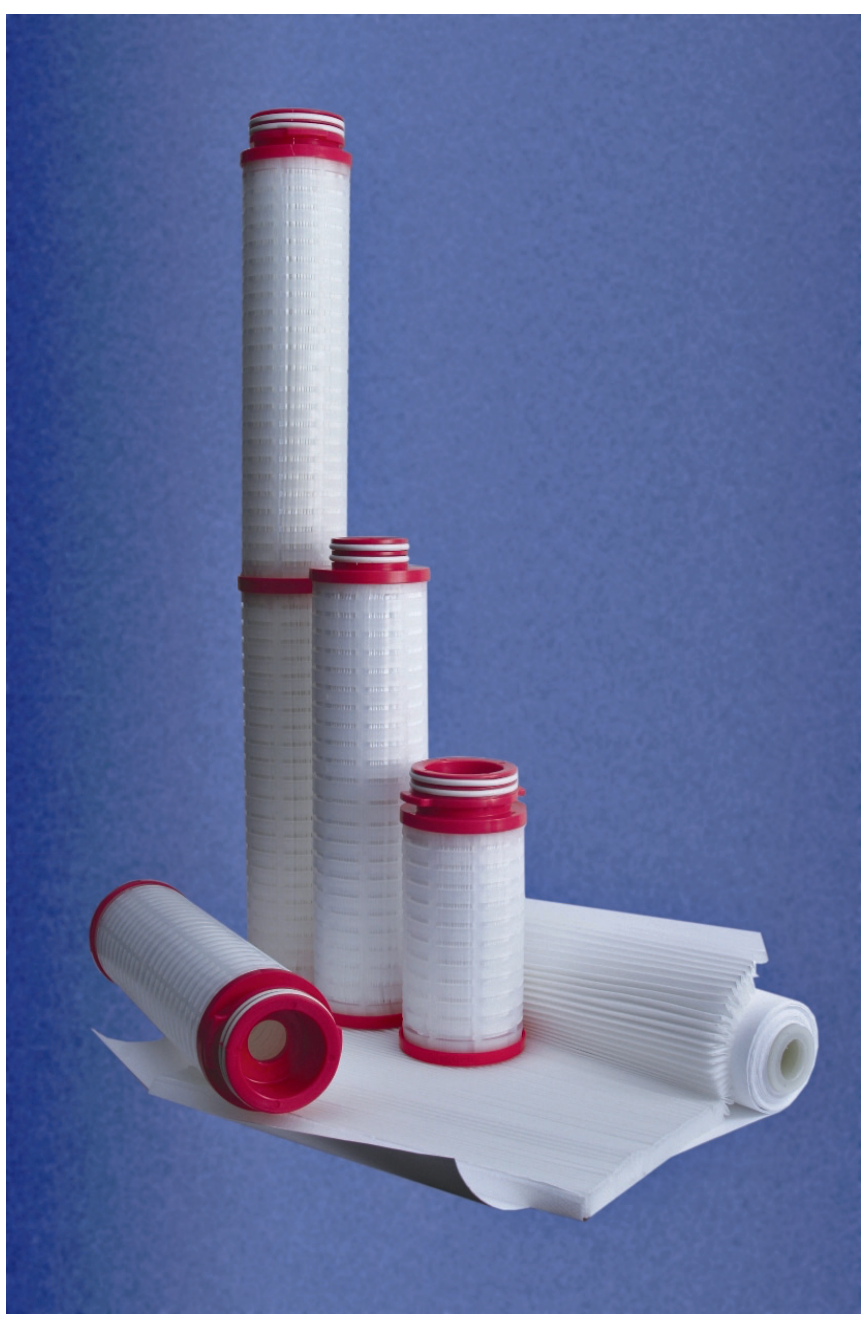

Рис. 4. Гофрированные фильтрующие элементы на основе «ЭКОПЛЕН-Ғ"

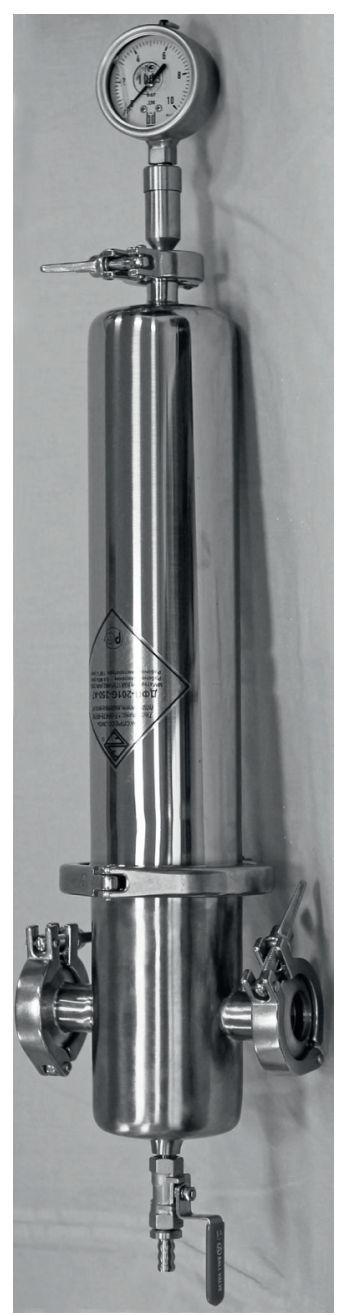

Рис. 5. Фильтро-

ДФП-201G-250-A7-1 держатель

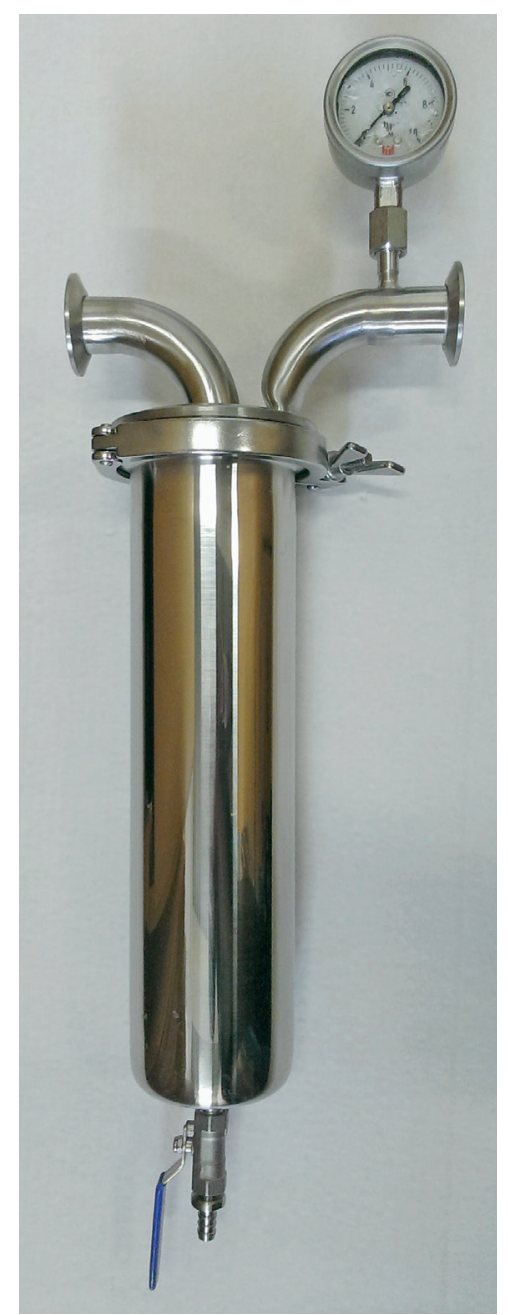

Рис. 6. Фильтродержатель ДФП-201C-250-A7-2
Фильтроэлементы можно регенерировать прямым и обратным током пароводяной смесью, острым паром в линии, стерилизовать в автоклаве, а также применять другие способы очистки и регенерации.

Помимо фильтрации от механических включений фильтроэлементы из фторопласта обеспечивают очистку от аэрозольных примесей. Поскольку фторопласт - гидрофобный материал, пары влаги и масло сепарируются на поверхности фильтроэлемента с последующим образованием капель, которые стекают под действием силы тяжести.

\section{ФИЛЬТРАЦИЯ ДЕИОНИЗОВАННОЙ ВОДЫ}

Для сохранения электросопротивления высокоомной воды используются фильтродержатели и фильтрующие элементы, изготовленные полностью из фторопласта-4 - материала с уникальной химической чистотой, что гарантирует отсутствие выделений в фильтрат 
и позволяет их эксплуатировать при очистке особо чистых жидкостей.

ГК "Обнинские фильтры» выпускает однопатронные фильтродержатели из фторопласта-4 марки ДФП-001L (рис. 7). Их корпус изготовлен из политетрафторэтилена марки «Фторопласт-4». Фильтродержатель снабжен посадочным местом под фильтроэлемент высотой 125 или 250 мм, максимальное рабочее давление составляет 4 атм, максимальная рабочая температура 170 ㄷ. Корпус фильтродержателя комплектуется спускным штуцером, имеет посадочное место А7 (диаметром 56,5 мм, с байонетным затвором) или посадочное место с внешней резьбой 3/4 дюйма. Габаритные размеры: высота около 600 мм, ширина около 200 мм. Для подсоединения к линии применяется штуцер из фторопласта-4 под шланг или с резьбой необходимого размера. Выполненные в основании корпуса входной и выходной фланцы позволяют производить замену фильтрующих элементов при снятом корпусе без отсоединения внешних трубопроводов. Фильтродержатель снабжен ножками для стационарной установки на полу или любой горизонтальной опорной поверхности.

Для фильтрации деионизованной воды предлагаетфторопласта-4 (торговая марка «ЭКОПЛАСТ-F») высотой 125 или 250 мм (установленные по одной штуке в фильтродержатель) с рейтингом фильтрации 0,2 мкм.

Фильтроэлементы из фторопласта-4 инертны по отношению к деионизованной воде, не выделяют примесей в фильтрат, могут быть частично регенерированы ся использовать фильтроэлементы глубинного типа из

и использованы повторно. Материал фильтрующих элементов представляет собой многослойную, твердую, пористую структуру, толщина стенки составляет 22 мм . То есть сочетание в одном фильтроэлементе двух-трех фильтров дает возможность равномерно распределять грязевую нагрузку и обеспечивает повышенный ресурс работы.

\section{ФИЛЬТРАЦИЯ ЖИДКИХ ХИМИЧЕСКИ АГРЕССИВНЫХ СРЕД, В ТОМ ЧИСЛЕ ТРАВИТЕЛЕЙ, КИСЛОТ, ПЕРЕКИСИ ВОДОРОДА, СМЕСИ КАРО}

Для фильтрации химически активных и агрессивных сред предлагаются фильтроэлементы на основе химически стойких полимеров - СВМПЭ и фторопласта-4. Фильтроэлементы марки "ЭКОПЛАСТ-РЕ» (ЭФП-101) на базе СВМПЭ, представляющие собой полые цилиндры диаметром 65 мм, производятся с рейтингами фильтрации от 1 до 50 мкм. Рабочая температура этих изделий доходит до $100^{\circ} \mathrm{C}$

Фильтроэлементы из сверхвысокомолекулярного полиэтилена могут быть регенерированы обратным или прямым током кислотными либо щелочными растворами с учетом производственного регламента, принятого на конкретном предприятии. Однократный ресурс работы фильтроэлементов зависит от природы собираемого осадка. При проведении своевременных регенераций обратным током кислотными или щелочными растворами (в зависимости от природы осадка) и благодаря своей уникальной (среди патронных фильтрующих элемен-

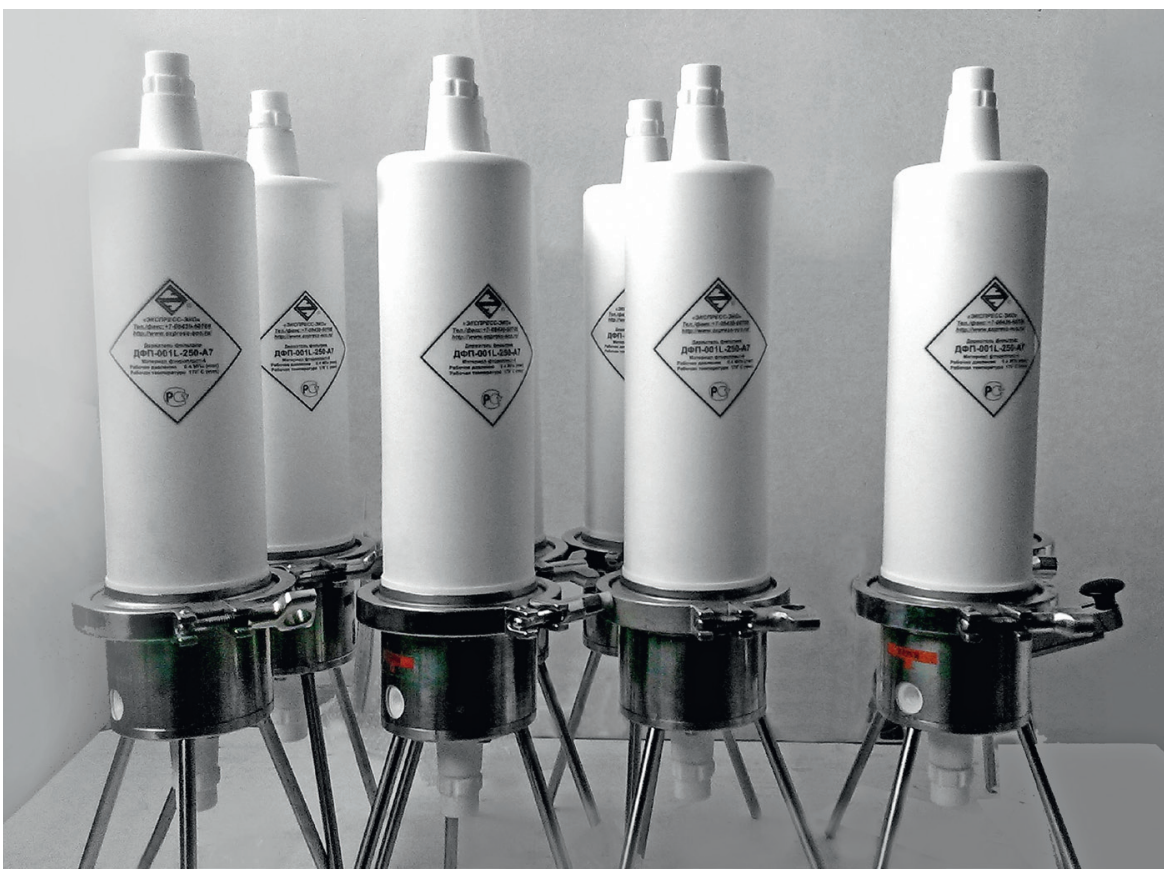
тов) механической прочности срок службы фильтроэлементов может исчисляться годами. Например, на фармацевтических предприятиях фильтроэлементы из сверхвысокомолекулярного полиэтилена используются до пяти лет

Фильтровать химически агрессивные жидкости можно с помощью фильтроэлементов глубинного типа марки "ЭКОПЛАСТ-F». В данном случае речь идет об использовании соответствующих элементов из фторопласта-4 для фильтрации особо агрессивных кислот, щелочей, растворов органических солей, перекиси водорода и пр. Перечень жидкостей достаточно широкий. Применение ПТФЭ марки Ф-4, который отличается уникальной химической стойкостью, может быть ограничено лишь условиями

Рис. 7. Фильтродержатели ДФП-001L 
эксплуатации - температура фильтрата не должна превышать $150^{\circ} \mathrm{C}$, перепад давления на фильтре не должен быть больше 0,5 МПа.

\section{ОЧИСТКА ГАЛЬВАНИЧЕСКИХ РАСТВОРОВ}

Фильтровать гальванические растворы можно двумя способами:

- в режиме рецикла - непрерывно, забирая раствор из ванны, фильтруя его и возвращая обратно в ванну уже очищенный;

- фильтровать из емкости, в которой находится грязный раствор, в другую емкость.

И в первом, и во втором случае необходимо использовать каскадный режим фильтрации. Задача финишных фильтров - обеспечение качества продукта фильтрации, а задача предварительного каскада - снижение грязевой нагрузки на финишный фильтр, что увеличивает ресурс работы фильтрационной системы в четыре-шесть раз.

Для фильтрации гальванических растворов предлагается использовать двухступенчатую фильтрационную установку, выполненную из двух последовательно соединенных фильтродержателей. Установка может быть смонтирована на единой раме с насосом, запорнорегулирующей арматурой и необходимой обвязкой. Обвязка трубопроводов выполнена таким образом, что нагнетательная и всасывающая линии насоса связаны одна

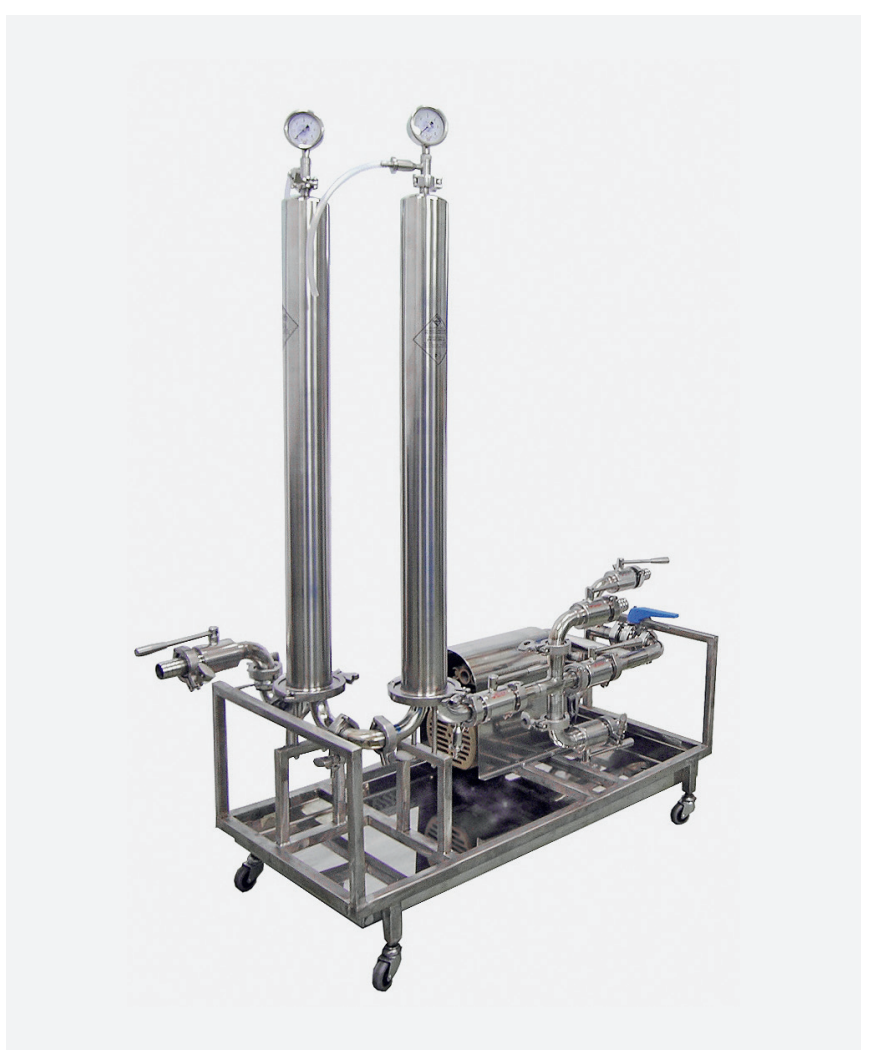

Рис. 8. Фильтрационная установка УФ-2 с другой байпасной линией, снабжены регулирующим вентилем. Такая система позволяет плавно регулировать скорость потока и давление жидкости на выходе с установки. В стандартном исполнении все металлические части фильтрационной установки, в том числе рабочая часть насоса и шаровые краны, выполнены из нержавеющей стали марки AISI 304 или AISI 316L (рис. 8). Возможны другие варианты компоновки и материала изготовления фильтрационных установок с учетом условий работы оборудования.

В качестве фильтрующего материала на стадии предварительной фильтрации рекомендуется установить фильтрующие элементы из сверхвысокомолекулярного полиэтилена с порогом задержания частиц 5-10 мкм. В качестве финишного фильтра предлагается использовать фильтрующие элементы из фторопласта-4 с порогом задержания частиц 0,5-1 мкм. Материал этих фильтроэлементов химически инертен и не выделяет примесей в фильтрат. Существует возможность частичной регенерации и многократного использования (фторопластовых - до пяти раз, полиэтиленовых - до 10-15 раз).

В заключение необходимо отметить, что перечисленные подходы - лишь часть решений ГК «Обнинские фильтры” для очистки жидкостей и газов, реализованных с помощью химически и термически стойких материалов на основе ПТФЭ и СВМПЭ. Помимо описанных в статье материалов, группа компаний предлагает фильтрующие элементы на основе мембран из политетрафторэтилена, полиэфирсульфона и полиамида с рейтингами фильтрации от 0,1 до 1 мкм. Также предприятие производит фильтрующие элементы на основе нержавеющих сеток в цельнометаллическом исполнении либо на полипропиленовом каркасе, фильтры из термоскрепленного, волокнистого полипропилена и др. [6].

\section{ЛИТЕРАТУРА}

1. Пашнин Ю.А., Малкевич С. Г., Дунаевская Ц. С. ФТоропласты. - Л.: Химия, 1978. 232 С

2. Андреева И. Н., Веселовская Е. В., Наливайко Е.И. Сверхвысокомолекулярный полиэтилен высокой плотности. - Л.: Химия, 1982. 80 с.

3. Астахов Е.Ю., Больбит Н. М., Клиншпонт Э. Р. Характеристики пористых пленок политетрафторэтилена, полученных из суспензий порошков в спирте // ВМС. Серия А. 2007. T. 49. № 2. С. 303-312.

4. Котова А. Ю. Четверть века фильтрам «Экспресс-Эко»! // Фармацевтические технологии и упаковка. Т. 272. № 6 . 2016. C. 42-43.

5. Baker. R. Microfiltration // Membrane Technology and Applications, 3rd edn. California: John Wiley \& Sons Ltd. 2012. P. 303-324.

6. Сайт Группы компаний "Обнинские фильтры". www.express-eco.ru/company/ 
Организатор

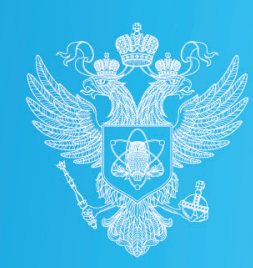

МИНИСТЕРСТВО НАУКИ

И ВЫСШЕГО ОБРАЗОВАНИЯ

\section{Наука}

Образование

Экономика

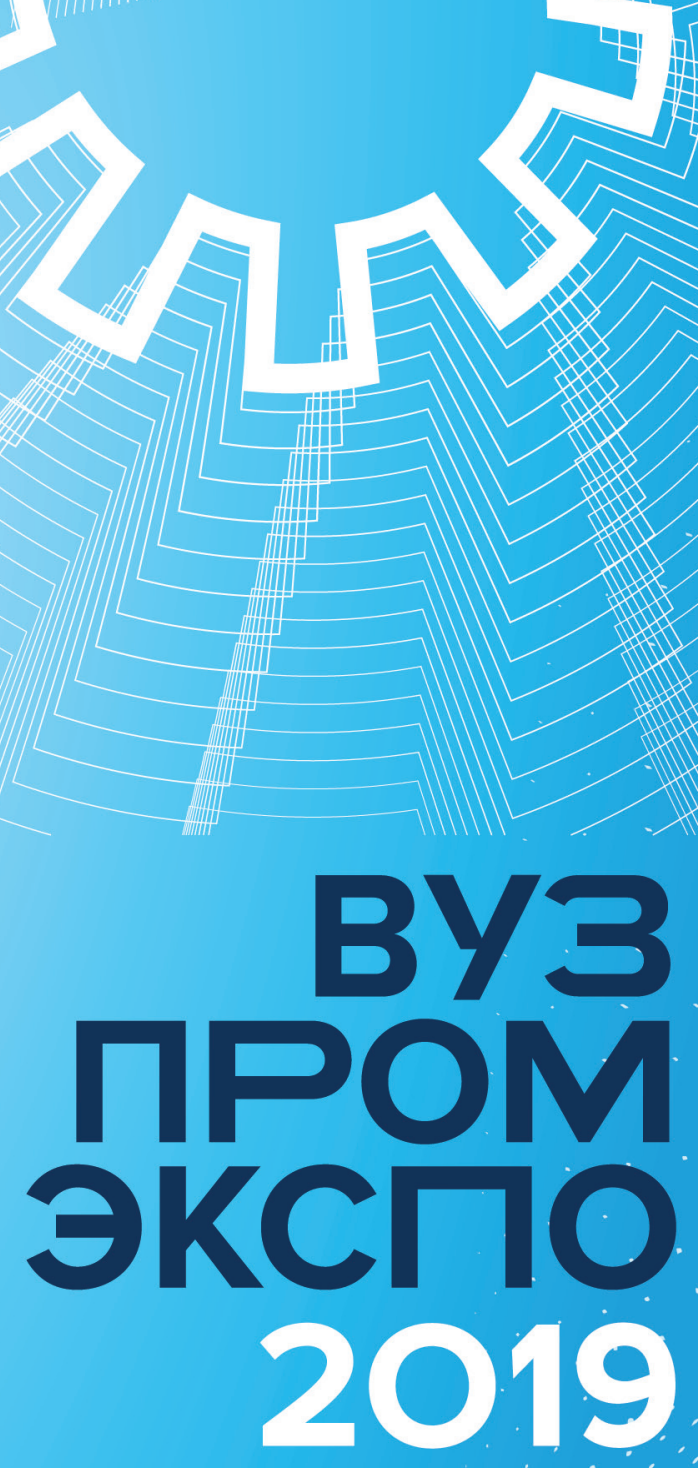

\section{1-12 ДЕКАБРЯ 2019 ЭКСПОЦLEHTP | MOCKВA}

VI ЕЖЕГОДНАЯ НАЦИОНАПЬҢНАЯ BGICTABKA 